\title{
Foreign Body Aspiration in Egyptian Children Clinical, Radiological and Bronchoscopic Findings
}

\author{
Heba M Reyad' \\ Mohamed E EL-Deeb (iD) ${ }^{2}$ \\ Ahmed M Abbas' \\ Dalia Sherief ${ }^{3}$ \\ Osama A Elagamy' \\ 'Department of Pediatrics, Faculty of \\ Medicine, Kafrelsheikh University, \\ Kafrelsheikh, Egypt; ${ }^{2}$ Department of \\ Otorhinolaryngology, Faculty of \\ Medicine, Kafrelsheikh University, \\ Kafrelsheikh, Egypt; ${ }^{3}$ Department of \\ Clinical Pathology, Faculty of Medicine, \\ Kafrelsheikh University, Kafrelsheikh, \\ Egypt
}

Purpose: Foreign body aspiration (FBA) is a frequent cause of childhood morbidity and mortality. Diagnosis of FBA is challenging in the absence of a witnessed aspiration event. The aim of this study was to determine the accuracy of presenting symptoms as well as physical and radiologic findings as predictors of FBA in children. Thus, indications for bronchoscopy could be determined in such cases.

Methods: This retrospective cohort study was conducted in the ENT department, Kafrelsheikh University Hospital. The medical records of patients younger than 16 years old who underwent rigid bronchoscopy for suspected FBA were included. Data including age, gender, symptoms, physical examination findings, radiological features, nature and location of foreign body, and outcome of the bronchoscopy were collected.

Results: This study included 130 patients, 105 (80.8\%) patients were positive for the presence of a foreign body in their airways. Foreign bodies were most frequently $(43.8 \%)$ lodged in the right main bronchus, and nuts $(66.7 \%)$, were the most commonly retrieved. Multivariate regression analysis identified the presence of suggestive signs or symptoms as independent predictors of FBA on rigid bronchoscopy.

Conclusion: Objective finding of clinical signs eg unilateral wheezes on chest examination in the presence of symptoms such as a sudden cough, dyspnea, and hoarseness could predict FBA and help physicians in deciding bronchoscopy.

Keywords: foreign body aspiration, rigid bronchoscopy, diagnosis, children, predictors

\section{Introduction}

Foreign body aspiration (FBA) is a critical condition that causes either complete or partial airway obstruction. Its incidence is more common in children than adolescents and adults, with a greater frequency between ages 1-3 years.,

Foreign body aspiration is a frequent cause of childhood morbidity and mortality. The overall death rate of FBA is approximately $5-7 \% .^{3}$ In the USA, about five hundred children die annually from FBA. ${ }^{4}$ In younger children, FBA has been reported as the fifth most common cause of unintentional deaths among 1-3 year olds, and the principal cause of accidental death in infants under 12 months. ${ }^{5}$

Furthermore, the frequency of complications varies from $14.6 \%$ to $27.8 \%$ of cases. ${ }^{6}$ The most commonly reported complications were pneumonia and respiratory distress. ${ }^{7}$ Greater rates of serious complications have been linked to delayed presentation, diagnosis, and management. 8,9

Diagnosis is challenging in the absence of a witnessed aspiration event by caregivers. Most symptoms and signs are nonspecific and may disappear rapidly. Only few cases show the classic triad of choking, cough, and unilateral wheezing or
Correspondence: Heba M Reyad

Tel +201010898038

Email h.reyad_00@hotmail.com 
diminished air entry. Moreover, some patients may not have any manifestations of FBA. ${ }^{10}$

A conventional chest X-ray could help in diagnosis of suspected cases of FBA. Abnormalities, including air trapping, segmental or lobe collapse or consolidation might be detected. However, these radiologic findings are nonspecific. Further, most of the aspirated foreign bodies are radiolucent such as food elements. In highly suspected cases of FBA, $\mathrm{CT}$ of the chest could establish the diagnosis. ${ }^{11}$

For saving the life of the patient, flexible or rigid bronchoscopy is the standard procedure used to extract the foreign body. This procedure has the drawbacks of being invasive, needs general anesthesia, and carries the risk of complications. Hence, its use should be limited to patients with a suspected diagnosis of FBA. ${ }^{12}$ However, there are no clinical clues that help physicians to confirm or exclude the diagnosis, thereby they could take the decision of opening the operation room for bronchoscopy.

Therefore, the aim of this study was to determine the accuracy of the presenting symptoms and the physical and radiologic findings as predictors of foreign body aspiration in children. Thus the criteria for bronchoscopy could be determined in such cases.

\section{Methods}

\section{Study Design and Setting}

This retrospective cohort study was conducted in the ENT department, Kafr-elsheikh University Hospital, during the period from April 2019 to January 2020.

\section{Study Population}

The study included all patients younger than 16 years old who underwent rigid bronchoscopy for suspected foreign body aspiration.

\section{Data Collection}

The medical records of all recruited children were reviewed. Data were summarized with respect to age, gender, complaint on admission, physical examination findings, radiological features, nature and location of foreign body and outcome of the bronchoscopy in an attempt to define the epidemiology, clinical presentation, management, and associated morbidity.

\section{Anesthesia}

All children underwent rigid bronchoscopy under general anesthesia with administration of neuromuscular blocking agents to induce muscle relaxation.

\section{Instrument}

Rigid bronchoscopes (Karl Storz) $2.5 \mathrm{~mm}, 3 \mathrm{~mm}, 3.5 \mathrm{~mm}$, $3.7 \mathrm{~mm}, 4 \mathrm{~mm}, 5 \mathrm{~mm}$, and $6 \mathrm{~mm}$ were used.

\section{Ethical Considerations}

The study protocol was approved from the Ethics Committee of the Faculty of Medicine, Kafr-elsheikh University in accordance with the Helsinki Declaration on clinical research involving human subjects. Approval for data collection from the medical records was obtained from Kafr-elsheikh University Hospital. The legal guardians of included children provided informed consent before treatment.

\section{Statistics}

Statistical analysis and presentation of data was conducted using the Statistical Package for the Social Sciences computer program (version 22). Categorical data were presented as numbers and percentages. The chi-square test was applied to investigate the association between categorical variables. When the expected cell sizes were less than 5, Fisher's exact tests was applied. For continuous data, they were tested for normality by Shapiro-Wilk test. For non-normally distributed continuous data, they were expressed in the median and interquartile range (25-75th percentiles) and the MannWhitney $U$-test was used for comparison between the studied groups. A binary logistic regression analysis was performed to determine the independent predictors of FBA from clinically and statistically significant variables with FBA. A p-value of $<0.05$ was considered statistically significant.

\section{Results}

This study included 130 patients younger than 16 years-old who underwent rigid bronchoscopy for suspected foreign body aspiration. About two-thirds (63.1\%) of them were males, and their median age was $2.0(\mathrm{IQR}=1.2-3.0)$ years. Out of the studied patients, 105 (80.8\%) showed the presence of a foreign body in the airway, which was successfully removed by rigid bronchoscopy. A significantly higher percentage of patients who had a foreign body were witnessed by a family member compared to those who revealed no foreign body aspiration $(73.3 \%$ and $12.0 \%$, respectively; $\mathrm{p}<0.001)$. The most frequent symptoms were sudden onset cough $(30.0 \%)$ and breathlessness (21.5\%). Choking and hoarseness were less common $(6.9 \%$ and $0.8 \%$, respectively). Additionally, there was a significant association between the presence of these symptoms and the detection of a foreign 
body $(\mathrm{p}=0.022)$. Regarding chest signs, diminished air entry $(37.7 \%)$ and wheezes $(28.5 \%)$ were the most common. It was found that a wheezy chest was significantly higher among patients who had a foreign body $(32.4 \%, \mathrm{p}=0.024)$, whereas chest crepitations were significantly higher among those who showed an absence of a foreign body $(16.0 \%, \mathrm{p}=0.005)$. Furthermore, the most common radiologic abnormalities were radiopaque shadow (7.7\%) and hyperinflation (3.1\%). However, the presence of chest X-ray abnormalities did not reveal significant association with the detection of a foreign body $(\mathrm{p}=0.361)$ as shown in Table 1 .
Table 2 shows that nuts $(66.7 \%)$ were the most frequently detected foreign body, followed by pins and metallic objects (5.7\% and 3.8\%, respectively). Concerning the site of the foreign body, right main bronchus, left main bronchus, lower trachea, and the subglottic area were the most frequent $(43.8 \%, 21.0 \%, 14.3 \%$, and $12.4 \%$, respectively).

Table 3 demonstrates a binomial logistic regression analysis model for the prediction of foreign body aspiration. In univariate analysis, the presence of symptoms was the only significant predictor of FB diagnosis on

Table I Demographic, Clinical, and Radiologic Criteria of Children Who Underwent Bronchoscopy for Suspected Foreign Body Aspiration

\begin{tabular}{|c|c|c|c|c|c|c|c|c|}
\hline & & & Pre & ce o & reign $B$ & & & \\
\hline & & $N=\mathbf{I}$ & $\begin{array}{l}\text { s } \\
80.8 \%)\end{array}$ & $\mathbf{N}=$ & $\begin{array}{l}\text { o } \\
\text { (9.2\%) }\end{array}$ & & & \\
\hline & & $\mathbf{N}$ & $\%$ & $\mathbf{N}$ & $\%$ & $\mathbf{N}$ & $\%$ & $\mathbf{P}$ \\
\hline Age (Median and IQR & & & $-3.0)$ & & $\mid-3.0)$ & 2.0 & $2-3.0)$ & 0.356 \\
\hline Sex & Female & 40 & $38.1 \%$ & 8 & $32.0 \%$ & 48 & $36.9 \%$ & 0.570 \\
\hline & Male & 65 & $61.9 \%$ & 17 & $68.0 \%$ & 82 & $63.1 \%$ & \\
\hline History & No & 28 & $26.7 \%$ & 22 & $88.0 \%$ & 50 & $38.5 \%$ & $<0.00 I^{*}$ \\
\hline & Witnessed & 77 & $73.3 \%$ & 3 & $12.0 \%$ & 80 & $61.5 \%$ & \\
\hline Symptoms & No & 45 & $42.9 \%$ & 3 & $12.0 \%$ & 48 & $36.9 \%$ & $0.022 *$ \\
\hline & Cough & 28 & $26.7 \%$ & II & $44.0 \%$ & 39 & $30.0 \%$ & \\
\hline & Breathlessness & 20 & $19.0 \%$ & 8 & $32.0 \%$ & 28 & $21.5 \%$ & \\
\hline & Chocking & 7 & $6.7 \%$ & 2 & $8.0 \%$ & 9 & $6.9 \%$ & \\
\hline & Breathlessness, chocking and cough & 4 & $3.8 \%$ & 0 & $0.0 \%$ & 4 & $3.1 \%$ & \\
\hline & Hoarseness & I & $1.0 \%$ & I & $4.0 \%$ & 1 & $0.8 \%$ & \\
\hline Diminished air entry & No & 62 & $59.0 \%$ & 19 & $76.0 \%$ & 81 & $62.3 \%$ & 0.116 \\
\hline & Yes & 43 & $41.0 \%$ & 6 & $24.0 \%$ & 49 & $37.7 \%$ & \\
\hline Unilateral Wheeze & No & 71 & $67.6 \%$ & 22 & $88.0 \%$ & 93 & $71.5 \%$ & $0.042 *$ \\
\hline & Yes & 34 & $32.4 \%$ & 3 & $12.0 \%$ & 37 & $28.5 \%$ & \\
\hline Stridor & No & 75 & $71.4 \%$ & 21 & $84.0 \%$ & 96 & $73.8 \%$ & 0.199 \\
\hline & Yes & 30 & $28.6 \%$ & 4 & $16.0 \%$ & 34 & $26.2 \%$ & \\
\hline Crepitations & No & 104 & $99.0 \%$ & 21 & $84.0 \%$ & 125 & $96.2 \%$ & $0.005^{*}$ \\
\hline & Yes & I & $1.0 \%$ & 4 & $16.0 \%$ & 5 & $3.8 \%$ & \\
\hline X-ray findings & Irrelevant & 87 & $82.9 \%$ & 23 & $92.0 \%$ & 110 & $84.6 \%$ & 0.160 \\
\hline & Radiopaque shadow & 10 & $9.5 \%$ & 0 & $0.0 \%$ & 10 & $7.7 \%$ & \\
\hline & Hyperinflation & 4 & $3.8 \%$ & 0 & $0.0 \%$ & 4 & $3.1 \%$ & \\
\hline & Collapse & 2 & $1.9 \%$ & 0 & $0.0 \%$ & 2 & $1.5 \%$ & \\
\hline & Lobar consolidation & I & $1.0 \%$ & 2 & $8.0 \%$ & 3 & $2.3 \%$ & \\
\hline & Scattered opacities & 1 & $1.0 \%$ & 0 & $0.0 \%$ & I & $0.8 \%$ & \\
\hline X-ray findings & Abnormal & 18 & $17.1 \%$ & 2 & $8.0 \%$ & 20 & $15.4 \%$ & 0.361 \\
\hline & Normal & 87 & $82.9 \%$ & 23 & $92.0 \%$ & 110 & $84.6 \%$ & \\
\hline
\end{tabular}

Note: *Significant at $\mathrm{p}<0.05$. 
Table 2 Frequency of Type and Site of the Detected Foreign Body

\begin{tabular}{|c|c|c|c|}
\hline & & $N=105$ & $\%$ \\
\hline \multirow[t]{14}{*}{ Type of foreign body } & Nuts & 70 & $66.7 \%$ \\
\hline & Pin & 6 & $5.7 \%$ \\
\hline & Lupine & 5 & $4.8 \%$ \\
\hline & Metallic object & 4 & $3.8 \%$ \\
\hline & Corn & 4 & $3.8 \%$ \\
\hline & Seed & 3 & $2.9 \%$ \\
\hline & Pen cap & 3 & $2.9 \%$ \\
\hline & Paper & 3 & $2.9 \%$ \\
\hline & Plastic piece & 2 & $1.9 \%$ \\
\hline & Meat & I & $1.0 \%$ \\
\hline & Fish bone & I & $1.0 \%$ \\
\hline & Chicken bone & I & $1.0 \%$ \\
\hline & Button & I & $1.0 \%$ \\
\hline & Bead & I & $1.0 \%$ \\
\hline \multirow[t]{10}{*}{ Site of foreign body } & Right main bronchus & 46 & $43.8 \%$ \\
\hline & Left main bronchus & 22 & $21.0 \%$ \\
\hline & Lower trachea & 15 & $14.3 \%$ \\
\hline & Subglottic & 13 & $12.4 \%$ \\
\hline & Trachea & 4 & $3.8 \%$ \\
\hline & Subglottic, Rt and Lt main bronchus & 1 & $1.0 \%$ \\
\hline & Subglottic and Rt main bronchus & I & $1.0 \%$ \\
\hline & Rt main bronchus andleft main bronchus & I & $1.0 \%$ \\
\hline & Glottis and subglottic & I & $1.0 \%$ \\
\hline & Glottis & I & $1.0 \%$ \\
\hline
\end{tabular}

Table 3 Predictors of Foreign Body Confirmation on Bronchoscopy

\begin{tabular}{|l|c|c|c|c|c|c|}
\hline \multirow{2}{*}{} & \multicolumn{3}{|c|}{ Univariate Analysis } & \multicolumn{3}{c|}{ Multivariate Analysis } \\
\cline { 2 - 7 } & OR & $\mathbf{9 5 \%} \mathbf{C l}$ & $\mathbf{P}$ & $\mathbf{O R}$ & $\mathbf{9 5 \%} \mathbf{C l}$ & $\mathbf{P}$ \\
\hline Age & 0.84 & $0.64-1.09$ & 0.18 & 0.83 & $0.64-1.08$ & 0.16 \\
Sex & 1.31 & $0.52-3.31$ & 0.57 & - & - & - \\
Symptoms & 0.21 & $0.06-0.73$ & 0.014 & 6.11 & $1.57-23.8$ & 0.009 \\
Signs & 2.1 & $0.83-5.45$ & 0.12 & 0.24 & $0.078-0.72$ & 0.011 \\
X-ray & 2.38 & $0.52-11.0$ & 0.27 & - & - & - \\
\hline
\end{tabular}

bronchoscopy [OR (95\% CI): $0.21(0.06-0.73, \mathrm{p}=0.014)]$. However, in multivariate analysis, significant predictors of FB on bronchoscopy included the presence of symptoms [OR (95\%) CI: $6.11(1.57-23.8), \mathrm{p}=0.009]$ and the presence of clinical signs [OR (95\% CI): $0.24(0.078-0.72)$, $\mathrm{p}=0.011]$.

\section{Discussion}

Foreign body aspiration always needs rapid intervention to prevent serious complications. However, its accurate diagnosis and ultimate decision for bronchoscopy remains challenging. ${ }^{13}$ Unfortunately, there is no global consensus for consistent decision making, with an observed great discrepancy among different institutions regarding reliable criteria for bronchoscopy in those children. ${ }^{14}$

In this study, the majority (80.8\%) of children who underwent rigid bronchoscopy for suspected FBA showed a foreign body in the airways. Similar studies in different countries reported variable rates from $25 \%$ up to $90 \%$ for positive bronchoscopy. ${ }^{14-18}$ Different strategies regarding indications for bronchoscopy could explain the diverse rates of positive bronchoscopies among different hospitals around the world. ${ }^{14}$ 
In the current study, the median age of children who aspirated foreign bodies was $2.0(\mathrm{IQR}=1.2-3.0)$ years. Likewise, it has been reported that FBA is highly frequent in age groups less than 4 years, and it occurs in only $5 \%$ of children aged 4-14 years. ${ }^{19}$ Children younger than 3 years have great curiosity, and they usually explore things by placing them into their mouth. So, they have an increased risk of FBA especially in the absence of parental supervision. ${ }^{20}$

Concerning the site where the foreign body was detected, the right and left main bronchi were the most frequent $(43.8 \%$ and $21.0 \%$, respectively). Other sites, including lower trachea (14.3\%) and the subglottic area (12.4\%), were less frequent. This is in agreement with Eren et $\mathrm{al}^{21}$ who reported that right main bronchus $(60 \%)$ followed by left main bronchus $(23 \%)$ were the most common sites for foreign bodies' lodgment while, the frequency of tracheal $(13 \%)$ and laryngeal foreign bodies $(3 \%)$ were less common. It is known that the right main bronchus has a more acute angle and wider caliber compared to the rest of the tracheobronchial tree. ${ }^{22}$

In this study, the most commonly retrieved foreign bodies were nuts $(66.7 \%)$, followed by pins and other metallic objects $(5.7 \%$ and $3.8 \%$, respectively). Similar reports found that nuts were the most common aspirated foreign bodies in children, ${ }^{23,24}$ whereas a review about FBA in South African children revealed a high frequency for metal and plastic foreign bodies ( $44 \%$ and $21 \%$, respectively). ${ }^{25}$ Another study detected food materials in the majority of cases and explained this by inadequate airway protection in children due to a lack of coordination of pharyngeal swallow, respiratory, and esophageal functions. ${ }^{26}$

Definite diagnosis of FBA requires a high index of clinical suspicion especially in the absence of a clear history of witnessed foreign body aspiration. This mandates detailed history and physical examination as well as chest radiography. ${ }^{27}$ It has been reported that common clinical symptoms associated with FBA are acute episodes of choking, coughing or wheezing, and unilateral abnormal or reduced breath sounds. ${ }^{28-30}$ Accordingly, this work revealed that a sudden cough $(30.0 \%)$, breathlessness $(21.5 \%)$, diminished air entry $(37.7 \%)$, and wheezes $(28.5 \%)$ were the most frequent clinical manifestations. Furthermore, most patients (73.3\%) with positive bronchoscopy gave a history of a witnessed aspiration event. Comparable percentages were recorded by Zahran et al ${ }^{30}$ and this highlights the importance of history in cases of $\mathrm{FB}$ aspiration.
Furthermore, the current study explored a significant association of a history of witnessed FBA, the presence of symptoms like a cough, dyspnea, choking, and hoarseness at initial presentation, and wheezes on examination in relation to the detection of a foreign body in the airways. This is comparable with previous studies. ${ }^{31,32}$ Conversely, Kwok et $\mathrm{al}^{33}$ reported the absence of a significant difference for children with and without FBA and a clinical history of aspiration, auscultation, and radiographic abnormalities. Though their study was limited by a small sample size (43 participants), it was valuable to evaluate children with suspected FBA for viral respiratory infection especially in infants younger than 1 year. $^{34}$

In this study, hyperinflation was more commonly found than consolidation or collapse. This agrees with Sahadan et al. ${ }^{35}$ On the contrary, Chouhan et $\mathrm{al}^{36}$ reported a collapse in most of their cases. However, the presence of chest X-ray abnormalities in the current study was not statistically different in children with or without evident FBA.

In fact, rigid bronchoscopy remains the gold standard for the definitive diagnosis and management of $\mathrm{FBA}^{37}$ It is rarely associated with serious complications, including upper and lower airway trauma, laryngospasm, bronchospasm and/or pneumothorax. ${ }^{38}$ There are some reports of possible general anesthesia-linked neurocognitive impairment, behavioral, and emotional consequences in early childhood. ${ }^{39}$ There is a need for consistent criteria for deciding bronchoscopy for removal of aspirated foreign bodies. This guarantees adequate management of cases at high risk for FBA, as well as avoiding unnecessary intervention in those cases with a very low chance of aspiration. ${ }^{14}$

In the present study, multivariate regression analysis identified the presence of relevant symptoms or signs as independent predictors of FB identification by rigid bronchoscopy. This is in agreement with earlier studies, ${ }^{14,15}$ which reported that as long as children with a suspected foreign body remain asymptomatic with no chest wheezes, the likelihood of FBA is low, and rigid bronchoscopy is not indicated. Likewise, our findings are consistent with Sink et $\mathrm{al}^{40}$ who reported that chest wheezes combined with decreased breath sounds had increased odds of FBA. Additionally, Divarci et $\mathrm{al}^{41}$ concluded that the presence of a positive history as well as clinical and radiologic findings together showed high sensitivity (91\%) in predicting FBA. An earlier prospective study highlighted the presence of a radiopaque $\mathrm{FB}$, and associated unilaterally decreased breath sounds and obstructive emphysema as statistically significant predictors of FBA. ${ }^{42}$ 
Likewise, the recent study of Özyüksel et al ${ }^{43}$ proposed a scoring system that incorporated physical findings and radiological parameters with high diagnostic performance in prediction of FBA in children.

\section{Conclusion}

Objective finding of clinical signs eg unilateral wheezes on chest examination in the presence of symptoms such as a sudden cough, dyspnea, and hoarseness could predict FBA and help physicians in deciding bronchoscopy.

\section{Disclosure}

The authors report no conflicts of interest for this work.

\section{References}

1. Jariwala N, Kratimenos P, Eng D, Gaughan J, Koutroulis I. Foreign body injuries in children: are the younger siblings doomed? Int $J$ Pediatr Adolesc Med. 2016;3(1):7-11. doi:10.1016/j. ijpam.2015.12.004

2. Saki N, Nikakhlagh S, Heshmati SM. 25-year review of the abundance and diversity of radiopaque airway foreign bodies in children. Indian J Otolaryngol Head Neck Surg. 2015;67(3):261-266. doi:10.1007/s12070-014-0817-0

3. Foltran F, Ballali S, Rodriguez H, et al. Inhaled foreign bodies in children: a global perspective on their epidemiological, clinical, and preventive aspects. Pediatr Pulmonol. 2013;48(4):344-351. doi:10.1002/ppul.22701

4. Grassi R, Faggian A, Somma F, De Cecco CN, Laghi A, CaseiroAlves F. Application of imaging guidelines in patients with foreign body ingestion or inhalation: literature review. Semin Ultrasound $C T$ MR. 2015;36(1):48-56. doi:10.1053/j.sult.2014.10.004

5. National Safety Council. National Safety Council; Injury Facts; 2017. Available from: https://injuryfacts.nsc.org. Accessed 20 October 2020.

6. Tatsanakanjanakorn W, Suetrong S. Do times until treatment for foreign body aspiration relate to complications? Int $J$ Otolaryngol. 2016;2016:2831614. doi:10.1155/2016/2831614

7. Rodríguez H, Cuestas G, Botto H, et al. Complications in children from foreign bodies in the airway. Acta Otorrinolaringol Esp. 2016;67(2):93-101. English, Spanish. doi:10.1016/j. otorri.2015.01.003

8. Shlizerman L, Mazzawi S, Rakover Y, Ashkenazi D. Foreign body aspiration in children: the effects of delayed diagnosis. $\mathrm{Am}$ $J \quad$ Otolaryngol. 2010;31(5):320-324. doi:10.1016/j. amjoto.2009.03.007

9. Chen X, Zhang C. Foreign body aspiration in children: focus on the impact of delayed treatment. Int $J$ Pediatr Otorhinolaryngol. 2017;96:111-115. doi:10.1016/j.ijporl.2017.03.013

10. Lowe DA, Vasquez R, Maniaci VJ. Foreign body aspiration in children. Clin Pediatr Emerg Med. 2015;16(3):140-148. doi:10.1016/j.cpem.2015.07.002

11. Park YM, Kim K, Lee HJ, et al. Chest radiographs and computed tomography scans in children with airway foreign body. Allergy Asthma Respir Dis. 2018;6(5):241-247. doi:10.4168/ aard.2018.6.5.241

12. Tenenbaum T, Kähler G, Janke C, Schroten H, Demirakca S. Management of foreign body removal in children by flexible bronchoscopy. J Bronchology Interv Pulmonol. 2017;24(1):21-28. doi:10.1097/LBR.0000000000000319
13. Hewlett JC, Rickman OB, Lentz RJ, Prakash UB, Maldonado F. Foreign body aspiration in adult airways: therapeutic approach. J Thorac Dis. 2017;9(9):3398-3409. doi:10.21037/jtd.2017.06.137

14. Janahi IA, Khan S, Chandra P, et al. A new clinical algorithm scoring for management of suspected foreign body aspiration in children. BMC Pulm Med. 2017;17(1):61. doi:10.1186/s12890-017-0406-6

15. Cohen S, Avital A, Godfrey S, Gross M, Kerem E, Springer C. Suspected foreign body inhalation in children: what are the indications for bronchoscopy? J Pediatr. 2009;155(2):276-280. doi:10.1016/j.jpeds.2009.02.040

16. Schmidt H, Manegold BC. Foreign body aspiration in children. Surg Endosc. 2000;14(7):644-648. doi:10.1007/s004640000142

17. Black RE, Johnson DG, Matlak ME. Bronchoscopic removal of aspirated foreign bodies in children. J Pediatr Surg. 1994;29 (5):682-684. doi:10.1016/0022-3468(94)90740-4

18. Emir H, Tekant G, Beşik C, et al. Bronchoscopic removal of tracheobroncheal foreign bodies: value of patient history and timing. Pediatr Surg Int. 2001;17(2-3):85-87. doi:10.1007/s003830000485

19. Zang C-S, Sun J, Huang H-T, et al. Inhaled foreign bodies in pediatric patients: a review and analysis of 3028 cases. Int J Clin Exp Pathol. 2017;10(1):97-104.

20. Williams A, George C, Atul PS, Sam S, Shukla S. An audit of morbidity and mortality associated with foreign body aspiration in children from a tertiary level hospital in Northern India. Afr J Paediatr Surg. 2014;11(4):287-292. doi:10.4103/0189-6725.143129

21. Eren S, Balci AE, Dikici B, Doblan M, Eren MN. Foreign body aspiration in children: experience of 1160 cases. Ann Trop Paediatr. 2003;23(1):31-37. doi:10.1179/000349803125002959

22. Fennira H, Ben Slimene D, Bourguiba M, et al. Corps étrangers trachéo-bronchiques de l'enfant. Aspects diagnostiques et thérapeutiques [Tracheobronchial foreign bodies. Diagnostic and therapeutic aspects in children]. Tunis Med. 2004;82(9):817-826.

23. Huankang Z, Kuanlin X, Xiaolin H, Witt D. Comparison between tracheal foreign body and bronchial foreign body: a review of 1007 cases. Int J Pediatr Otorhinolaryngol. 2012;76(12):1719-1725. doi:10.1016/j.ijporl.2012.08.008

24. Zhijun C, Fugao Z, Niankai Z, Jingjing C. Therapeutic experience from 1428 patients with pediatric tracheobronchial foreign body. $J \quad$ Pediatr Surg. 2008;43(4):718-721. doi:10.1016/j.jpedsurg. 2007.10.010

25. Sultan TA, van As AB. Review of tracheobronchial foreign body aspiration in the South African paediatric age group. $J$ Thorac Dis. 2016;8(12):3787-3796. doi:10.21037/jtd.2016.12.90

26. Boufersaoui A, Smati L, Benhalla KN, et al. Foreign body aspiration in children: experience from 2624 patients. Int $J$ Pediatr Otorhinolaryngol. 2013;77(10):1683-1688. doi:10.1016/j. ijporl.2013.07.026

27. Wang L, Zhang L, Li D, et al. Successful retrieval of a plastic bead from the airway of a child by flexible bronchoscopy and a balloon-tipped catheter: a case report and literature review. Medicine (Baltimore). 2018;97(37):e12147. doi:10.1097/ MD.0000000000012147

28. Dorterler ME, Kocaman OH, Gunendi T, Boleken ME. A single-center experience of pediatric foreign-body aspiration: a retrospective 4-year case series. Lung India. 2019;36(3):202-206.

29. Roda J, Nobre S, Pires J, Estêvão MH, Félix M. Foreign bodies in the airway: a quarter of a century's experience. Rev Port Pneumol. 2008;14(6):787-802. doi:10.1016/S0873-2159(15)30287-7

30. Zahran M, Youssef A. The role of rigid bronchoscopy in pediatric foreign body aspiration. Egypt J Otolaryngol. 2019;35(2):213-218.

31. Bakal Ü, Keleş E, Saraç M, Karlidağ T, Kaygusuz İ, Kazez A. A study of foreign body aspiration in children. J Craniofac Surg. 2016;27(4):e358-e363. doi:10.1097/SCS.0000000000002582

32. Holst-Albrechtsen S, Kristensen S, Larsen K. Bronchoscopy in children suspected of lower airway aspiration. Dan Med J. 2017;64(11): A5419. 
33. Kwok MM, Wong A, Paddle P, Goergen S, Rimmer JJ. Clinicoradiological predictors of positive rigid bronchoscopy findings in children with suspected tracheobronchial foreign body aspiration. Austral J Otolaryngol. 2018;1(2):11. doi:10.21037/ajo.2018.01.07

34. Sheehan CC, Lopez J, Elmaraghy CA. Low rate of positive bronchoscopy for suspected foreign body aspiration in infants. Int J Pediatr Otorhinolaryngol. 2018;104:72-75. doi:10.1016/j.ijporl.2017.10.030

35. Sahadan DZ, Zainudin NM, Kassim A, et al. Case series of foreign body aspiration in Paediatric Institute, Hospital Kuala Lumpur. Med J Malaysia. 2011;66(5):484-486.

36. Chouhan M, Sharma S. Tracheobronchial foreign bodies: the importance of timely intervention and appropriate collaboration. Indian J Otolaryngol Head Neck Surg. 2019;71(Suppl 1):972-975. doi:10.1007/s12070-019-01659-1

37. Gang W, Zhengxia P, Hongbo L, et al. Diagnosis and treatment of tracheobronchial foreign bodies in 1024 children. J Pediatr Surg. 2012;47(11):2004-2010. doi:10.1016/j.jpedsurg.2012.07.036

38. Stahl DL, Richard KM, Papadimos TJ. Complications of bronchoscopy: a concise synopsis. Int J Crit Illn Inj Sci. 2015;5(3):189-195. doi:10.4103/2229-5151.164995
39. Backeljauw B, Holland SK, Altaye M, Loepke AW. Cognition and brain structure following early childhood surgery with anesthesia. Pediatrics. 2015;136(1):e1-e12. doi:10.1542/peds.2014-3526

40. Sink JR, Kitsko DJ, Georg MW, Winger DG, Simons JP. Predictors of foreign body aspiration in children. Otolaryngol Head Neck Surg. 2016;155(3):501-507. doi:10.1177/0194599816644410

41. Divarci E, Toker B, Dokumcu Z, Musayev A, Ozcan C, Erdener A. The multivariate analysis of indications of rigid bronchoscopy in suspected foreign body aspiration. Int $J$ Pediatr Otorhinolaryngol. 2017;100:232-237. doi:10.1016/j.ijporl.2017.07.012

42. Martinot A, Closset M, Marquette $\mathrm{CH}$, et al. Indications for flexible versus rigid bronchoscopy in children with suspected foreign-body aspiration. Am J Respir Crit Care Med. 1997;155(5):1676-1679. doi:10.1164/ajrccm.155.5.9154875

43. Özyüksel G, Arslan UE, Boybeyi-Türer Ö, et al. New scoring system to predict foreign body aspiration in children. J Pediatr Surg. 2020;55(8):1663-1666. doi:10.1016/j.jpedsurg.2019.12.015
Journal of Multidisciplinary Healthcare

\section{Publish your work in this journal}

The Journal of Multidisciplinary Healthcare is an international, peerreviewed open-access journal that aims to represent and publish research in healthcare areas delivered by practitioners of different disciplines. This includes studies and reviews conducted by multidisciplinary teams as well as research which evaluates the results or conduct of such teams or healthcare processes in general. The journal

\section{Dovepress}

covers a very wide range of areas and welcomes submissions from practitioners at all levels, from all over the world. The manuscript management system is completely online and includes a very quick and fair peer-review system. Visit http://www.dovepress.com/testimonials. php to read real quotes from published authors. 